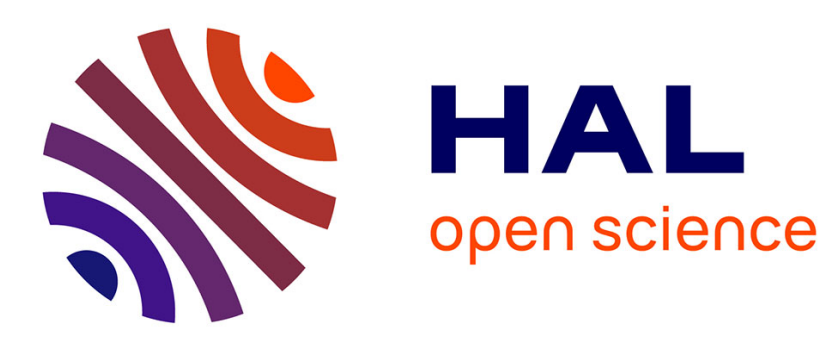

\title{
Psychophysical study of the effects of topical application of menthol in healthy volunteers.
}

\author{
Samar Hatem, Nadine Attal, Jean-Claude Willer, Didier Bouhassira
}

\section{To cite this version:}

Samar Hatem, Nadine Attal, Jean-Claude Willer, Didier Bouhassira. Psychophysical study of the effects of topical application of menthol in healthy volunteers.. Pain, 2006, 122 (1-2), pp.190-6. 10.1016/j.pain.2006.01.026 . hal-00272331

\section{HAL Id: hal-00272331 \\ https://hal.science/hal-00272331}

Submitted on 10 Sep 2008

HAL is a multi-disciplinary open access archive for the deposit and dissemination of scientific research documents, whether they are published or not. The documents may come from teaching and research institutions in France or abroad, or from public or private research centers.
L'archive ouverte pluridisciplinaire HAL, est destinée au dépôt et à la diffusion de documents scientifiques de niveau recherche, publiés ou non, émanant des établissements d'enseignement et de recherche français ou étrangers, des laboratoires publics ou privés. 
PSYCHOPHYSICAL STUDY OF THE EFFECTS OF TOPICAL APPLICATION OF MENTHOL IN HEALTHY VOLUNTEERS

Samar Hatem ${ }^{a, b}$, Nadine Attal $^{a}$, Jean-Claude Willer ${ }^{b}$ and Didier Bouhassira ${ }^{a}$

a) INSERM, U792, CHU Ambroise Paré, AP-HP, Boulogne-Billancourt, F92100 France; Université Versailles-Saint-Quentin, Versailles, F-78035 France

b) Service d'Explorations Fonctionnelles du Système Nerveux, CHU PitiéSalpêtrière, APHP, Paris, F-75013 France

Corresponding author: Didier Bouhassira MD, PhD. INSERM U-792

Centre d'Evaluation et de Traitement de la Douleur CHU Ambroise Paré

9, avenue Charles de Gaulle 92100 BOULOGNE-BILLANCOURT, FRANCE

Tel: $\quad+33149094556$

Fax: + 33149094435

e-mail: didier.bouhassira@apr.aphp.fr 


\begin{abstract}
Cold hyperalgesia is a major clinical phenomenon, but validated experimental models are still lacking for humans. Topical menthol application has recently been proposed as a possible model for the study of cold pain. We characterized the psychophysical effects of $30 \%$ L-menthol in ethanol on glabrous skin in 39 healthy subjects, using a double-blind, randomized, crossover design, with ethanol as a control. Psychophysical testing included an assessment of pain thresholds and detection of mechanical, cold and heat stimuli and of the sensations induced by suprathreshold stimuli. Most subjects (90 \%) perceived a cooling sensation with menthol. Menthol decreased cold pain thresholds and enhanced pain responses to suprathreshold noxious cold stimuli, without affecting responses to other stimuli. Menthol therefore has selective effects on noxious cold processing. No subject displayed signs of skin irritation or redness. These data suggest that $30 \%$ menthol application may be a useful experimental model for studies of cold hyperalgesia in humans. The absence of local skin reactions also makes this test potentially suitable for use in patients.
\end{abstract}

Key Words: menthol - quantitative sensory tests - cold hyperalgesia - cold allodynia - surrrogate models 


\section{Introduction}

Experimental models of hyperalgesia in humans have been developed in recent years as tools for investigating the mechanisms of clinical hyperalgesia (Klein et al., 2005). The topical or intradermal capsaicin model is currently the most widely used (Petersen and Rowbotham, 1999; Hughes et al., 2002; Dirks et al., 2003). Capsaicin induces long-lasting, stable, primary and secondary mechanical hyperalgesia. However, no validated experimental model is currently available for studies of cold hyperalgesia in humans, despite the importance of this clinical phenomenon and its observation in many patients with peripheral or central nervous system lesions (Verdugo and Ochoa 1994; Jensen et al., 2001;). The mechanisms of cold pain and cold hyperalgesia are therefore much less well understood than those of mechanical hyperalgesia (Davis, 1998). They are thought to involve a decrease in the inhibition normally exerted centrally by cold sensory channels on nociceptive channels (Wahren et al., 1989; Yarnitsky and Ochoa, 1990; Craig and Bushnell, 1994; Craig et al., 1996;), but peripheral mechanisms cannot be excluded (Wasner et al., 2004).

One possible model for studying cold hyperalgesia in humans is the topical application of menthol $\left(\mathrm{C}_{10} \mathrm{H}_{20} \mathrm{O}\right)$, a cyclic terpene alcohol widely used in topical preparations, such as anti-pruritic and anti-tussive formulations, nasal decongesting agents and analgesic creams. A specific menthol- and cold-sensitive nociceptor identified in animals - TRPM8 (McKemy et al., 2002; Preier et al., 2002) - has recently been cloned and shown to be expressed primarily in small-diameter neurons involved in sensing pain. The role of TRPM8 in cold pain in humans remains unclear, but psychophysical 
experiments have suggested that although menthol elicits a pleasant cool sensation when applied at low concentrations to the skin or mouth (Green, 1985, 1992; Yosipovitch et al., 1996; Cliff and Green 1994, 1996; Green and McAuliffe, 2000), it enhances pain perception at higher concentrations in normal subjects, provoking signs of cold and mechanical hyperalgesia (Wasner et al., 2004; Namer et al., 2005). However, the psychophysical attributes of the reactions induced by menthol, and its effects on the perceived pain intensity in response to various types of noxious stimuli in particular, have not yet been fully characterized, with results published for only a small number of subjects. It therefore remains unclear whether menthol may be considered a relevant human experimental model for studying cold pain, and whether it is suitable for use in patients with neuropathic pain.

In this study, we characterized the psychophysical effects of menthol on glabrous skin in healthy volunteers, using a double-blind, randomized, twoway crossover placebo-controlled design. We analyzed the detection of heat, cold and mechanical stimuli, pain thresholds and the sensations induced by suprathreshold stimulation, and assessed the function of large myelinated fibers by testing vibration thresholds. Our findings suggest that menthol application is a relevant experimental model for studying cold hyperalgesia in humans. 


\section{Methods}

\subsection{Subjects}

We included 39 healthy subjects, aged 20 to 35 years (19 women, 20 men, mean age: $24 \pm 3.8$ years) in this study. These subjects had no clinical history, clinical symptoms or signs of peripheral or central nervous system disorders. None of the subjects was on medication at the time of testing or in the month before testing. The study was approved by the local ethics committee. All subjects gave written informed consent and received information on the nature of the tests in accordance with the Helsinki Declaration.

\subsection{Menthol and vehicle}

We applied $2 \mathrm{ml}$ of 30\% L-menthol (Sigma-Aldrich, Munich, Germany) dissolved in $90 \%$ ethanol mixed with $1 \%$ polysorbate 80 (Tween 80 ) to a 2.5 X $5 \mathrm{~cm}$ gauze pad, which was placed on the right volar forearm, about $10 \mathrm{~cm}$ from the wrist. Preliminary testing, using various concentrations of menthol (from $5 \%$ to $40 \%$ ), in another group of healthy subjects had shown that $30 \%$ was the ideal menthol solution concentration for inducing a clear sensation of cold whilst avoiding excessive pain, flare-up reactions or skin irritation. Lower concentrations gave modest but not significant increases in cold sensation or pain, whereas higher concentrations induced intense burning pain, flare-up reactions or skin irritation in almost all the subjects. The gauze pad was covered with cling-film for 10 minutes, to prevent evaporation of the ethanol. The gauze pad was then removed and the skin wiped, to remove any remaining menthol. The control solution ( $2 \mathrm{ml}$ of $90 \%$ ethanol + Tween 80$)$ 
was applied to the skin in the same way.

The test and control solutions were coded by a technical assistant, who did not participate in subsequent experiments, and all subjects received either menthol or vehicle in a double-blind randomized crossover design, with an interval of one week between applications.

We placed a cotton pad imbibed with a drop of $30 \%$ menthol close to all subjects, such that the minty smell of menthol diffused into the air, masking olfactory clues as to the nature of the solution applied.

\subsection{Evaluation of spontaneous pain and thermal sensations}

The subjects were asked to report and describe the quality of any spontaneous painful or non painful sensation 10 minutes after the application of menthol or vehicle.

\subsection{Psychophysical testing}

Psychophysical tests were performed in subjects comfortably installed in a bed, in a quiet room, at a constant temperature $\left(22^{\circ} \mathrm{C}\right)$, by a single experienced investigator blind to the randomization. Tests were carried out at baseline (before applying the solution) and 10 minutes after the application of menthol or placebo, after removal of the gauze pad, at the precise site of application. Testing order was randomized and the assessments made included dynamic mechanical allodynia, determination of vibration thresholds, and mechanical and thermal (warm then cold) psychophysical testing. The experiments lasted about 90 minutes: 40 minutes of baseline testing, 10 minutes of application of menthol or ethanol and 40 minutes of post treatment testing. Before starting the experimental session, a series of thermal test 
stimuli were administered to the volar surface of the hand, to enable the subject to get used to the testing procedure.

\subsubsection{Vibration sensation}

Vibratory stimuli applied in an ascending order of magnitude with a vibrameter (Somedic) and vibration thresholds were determined using the method of limits (Lindblom and Tegner 1979).

\subsubsection{Mechanical sensations and pain}

The intensity of brush-induced (dynamic) mechanical allodynia was assessed by stroking the skin gently with a brush (3 times). Stimulus detection and pain thresholds for mechanical stimuli were assessed with calibrated von Frey hairs (0.057 to $140 \mathrm{~g}$ ) (Somedic, Sweden), as previously described (Bouhassira et al., 1999). Care was taken to avoid stroking the skin and to apply only one pressure stimulus. The subjects were instructed to close their eyes during the procedure. The filaments were applied (at least twice) during a two-second period, with increasing and then decreasing pressure. Detection thresholds were defined as the lowest pressure perceived by the subject, and pain thresholds were defined as the lowest pressure considered to be painful. The force required to bend the filaments $(0.057-140 \mathrm{~g})$ was then converted into log units. After determining the mechanical pain threshold, suprathreshold stimuli were applied in a pseudorandom order, using selected von Frey filaments, according to the same method described previously (Bouhassira et al., 1999). After each stimulus, the subjects were asked to quantify pain intensity on a $100 \mathrm{~mm}$ visual analog scale (VAS; from 0: no pain to 100 : maximal pain). If a VAS score of 80 or more was reported for a certain intensity, no stronger stimuli were applied. In such cases, the same VAS 
score was assigned to all higher stimuli, facilitating the analysis of cumulative group data. This method made it possible to plot mean stimulus/response curves for pain intensity as a function of graded nociceptive mechanical stimuli.

\subsubsection{Thermal sensations and pain}

Thermal sensations were assessed with a thermotest (Somedic $A B$, Stockholm, Sweden), using the Marstock method (Fruhstorfer et al., 1996). A contact thermode of Peltier elements measuring $2.5 \times 5 \mathrm{~cm}$ was applied to glabrous skin. A baseline temperature of $31.6^{\circ} \mathrm{C}$ and a thermal rate change of $1^{\circ} \mathrm{C} / \mathrm{s}$ were used. Thresholds were measured according to the method of limits previously described by Fruhstorfer et al. (1996): briefly, increasing or decreasing temperatures were applied; for each stimulus the subject was instructed to press a button that reversed the thermal stimulation, as soon as he or she detected the sensation of cold or warm (detection threshold) or as soon as the stimulation became painful (pain threshold). All thresholds were calculated as the means of three successive determinations. An interstimulus interval of 6 to $8 \mathrm{~s}$ was used when testing perception thresholds whereas intervals of 15 to $20 \mathrm{~s}$ were used for heat pain thresholds and of 20 to $30 \mathrm{~s}$ for cold pain thresholds. The maximum and minimum temperatures were set at $50^{\circ} \mathrm{C}$ and $5^{\circ} \mathrm{C}$, to prevent tissue damage.

After determining pain thresholds, a series of suprathreshold thermal stimuli $\left(5-50^{\circ} \mathrm{C}\right)$ were applied in a pseudorandom order, as previously described (Hansson and Lindblom 1992; Bouhassira et al. 1999). Each stimulus lasted $2 \mathrm{~s}$ and its intensity increased or decreased in steps of $2^{\circ} \mathrm{C}$ for heat stimuli and $2.5^{\circ} \mathrm{C}$ for cold stimuli. We left an interval of at least 1 minute 
between successive stimuli to prevent sensitization. After each stimulus, the volunteers were asked to rate pain intensity on a VAS. Subjects were informed that they could stop the stimulus at any time. If a VAS score of 80 or more was reported with a certain intensity, no stronger stimuli were applied. In such cases, the same VAS score was assigned to all stronger stimuli, to facilitate the analysis of cumulative group data. This method made it possible to plot mean stimulus/response curves for pain intensity against graded thermal stimuli. The same method was used for intensity-response curves for non noxious cooling and warming.

\subsection{Statistical analysis}

Data are expressed as means $\pm 1 \mathrm{SD}$. Analysis of variance (ANOVA) was used to compare the effects of menthol and placebo (vehicle) on stimulus detection and pain thresholds. Repeated-measures ANOVA was used to analyze the stimulus-response curves obtained for suprathreshold mechanical or thermal stimuli with menthol or placebo. In these analyses, the psychophysical thresholds and pain scores in response to suprathreshold stimuli were expressed as a difference between the baseline values and the values obtained after menthol or placebo application. The Kendall correlation test was used to examine correlations between the baseline psychophysical values and the effects of menthol on pain thresholds or responses to suprathreshold stimulation. The $c h i^{2}$ test was used to compare the proportions of subjects reporting spontaneous sensations in both treatment groups. In all instances, $p$ values less than 0.05 were regarded as significant. 


\section{Results}

\subsection{Spontaneous sensations evoked by menthol}

No subject reported spontaneous pain following menthol or vehicle application. Thirty-five subjects (90\% of the sample) reported a spontaneous sensation of coolness at the site of menthol application, whereas only one subject reported such a sensation after the placebo. Four subjects (10\%) perceived a sensation of warmth with menthol, which was not observed after application of the placebo.

\subsection{Effects of menthol on responses to cold stimuli}

Baseline cold detection thresholds were not significantly different for menthol and vehicle $\left(30.7 \pm 0.8{ }^{\circ} \mathrm{C}\right.$ and $30.8 \pm 1.2{ }^{\circ} \mathrm{C}$ respectively). Cold detection thresholds increased moderately but significantly after ethanol but not menthol application (Table 1).

Cold pain thresholds at baseline were not significantly different for menthol and vehicle $\left(14.2 \pm 7^{\circ} \mathrm{C}\right.$ and $13.5 \pm 6.9^{\circ} \mathrm{C}$, respectively). They were significantly increased by menthol but not by placebo indicating allodynia to cold (Fig 1 A). In addition, pain scores in response to suprathreshold noxious cold stimuli were significantly higher after menthol than after placebo, indicating cold hyperalgesia (Fig. 2 A). Pain was most commonly described as "burning" (77 \% of cases), less commonly as "cold pain" or "tingling" (23\%) in the menthol group, but $59 \%$ of the subjects also described "burning" pain after vehicle application $(p>0.05)$. In contrast to what was observed for noxious cold, the intensity-response curve for non noxious cooling stimulation was not modified by application of menthol or vehicle (not shown). 
No correlation was found between baseline cold pain thresholds and the psychophysical effects of menthol on cold pain.

Seven subjects (18\% of the sample) experienced no cold pain at the lowest temperature used in this study $\left(5^{\circ} \mathrm{C}\right)$ and were considered to have high cold pain thresholds at baseline. These subjects did not differ from the others in their responses to other stimuli at baseline (warmth detection thresholds: $32.9 \pm 0.5{ }^{\circ} \mathrm{C}$, heat pain thresholds: $44.4 \pm 3.2{ }^{\circ} \mathrm{C}$, mechanical thresholds: $1.7 \pm 0.2 \log (\mathrm{mg})$; mechanical pain thresholds: $3.7 \pm 0.1 \log (\mathrm{mg})$; vibration thresholds: $2.8 \pm 1.8 \mathrm{~mA}$ ). They had responses similar to those of the other subjects to the psychophysical effects of menthol on cold pain thresholds and on responses to suprathreshold cold stimuli.

Thirteen subjects (33\%) displayed no signs of cold allodynia or hyperalgesia after menthol application and six even had lower pain scores in response to noxious cold after menthol: they were considered to be "poor responders" or "non responders" to $30 \%$ menthol under our experimental conditions. The baseline characteristics of these subjects were similar to those of the others (cold detection thresholds: $30.6 \pm 0.8{ }^{\circ} \mathrm{C}$; cold pain thresholds: $15.7 \pm 16.8^{\circ} \mathrm{C}$; warmth detection thresholds: $33.3 \pm 0.7^{\circ} \mathrm{C}$; heat pain thresholds: $44.2 \pm 2.3^{\circ} \mathrm{C}$; mechanical detection thresholds: $1.8 \pm 0.1$; mechanical pain thresholds: $4.4 \pm 0.4$; vibration thresholds: $3.9 \pm 2.9 \mathrm{~mA}$ ).

\subsection{Effects of menthol on responses to warm/heat stimuli}

The baseline warmth detection and heat pain thresholds were not significantly different for menthol $\left(33.1 \pm 0.5{ }^{\circ} \mathrm{C}\right.$ for warmth detection; $43.6 \pm$ 2.5 for heat pain) and placebo (33.2 \pm 0.7 for warmth detection: $43.3 \pm 2.6$ for heat pain) and were not significantly modified by the application of menthol or 
vehicle (Table 1, Fig. 1B). There was no evidence for heat hyperalgesia after menthol or vehicle application (Fig. 2 B). The intensity-response curves for non noxious warming were not affected by menthol or placebo application (not shown).

3.4. Effects of menthol on responses to mechanical and vibration stimuli

We found no evidence of brush-evoked allodynia after menthol or placebo application. The baseline mechanical detection and pain thresholds were similar for menthol and vehicle $(1.8 \pm 0.1 \log (\mathrm{mg})$ for detection thresholds; $4.7 \pm 0.4 \log (\mathrm{mg})$ for pain thresholds in both groups) and were not modified by the application of menthol or placebo (Table 1, Fig. 1C). In addition, pain scores in response to mechanical pinprick stimuli were similar at baseline and were not significantly modified by the application of menthol or placebo (Fig. 2 C).

Similarly, the vibration thresholds did not differ significantly between menthol and placebo applications $(3.6 \pm 2.5 \mathrm{~mA}$ and $3.2 \pm 2 \mathrm{~mA}$ for menthol and the placebo, respectively) and were unaffected by these applications (Table 1).

\subsection{Side effects}

No side effects were recorded with menthol or with vehicle. In particular, there was no redness of the skin or signs of inflammation or skin irritation in any of the subjects. 


\section{Discussion}

The results of this psychophysical study demonstrate that topical $30 \%$ L-menthol application to glabrous skin in healthy subjects selectively modulates responses to noxious cold. Two recent psychophysical studies also reported that topical menthol reduced cold pain thresholds in healthy subjects (Wasner et al., 2004; Namer et al., 2005). Only one previous study detected no significant effects of menthol on cold pain thresholds, but these negative findings were probably due to unstable baseline values for noxious cold and the use of very low concentrations of menthol (Yosipovitch et al., 1996). Our data indicate that both pain thresholds and the intensity of pain elicited by suprathreshold noxious cold stimuli are modulated by menthol. It has recently been demonstrated in vitro that menthol specifically targets a cold and menthol receptor - TRPM8 - expressed primarily on C fiber afferents (McKemy et al., 2002; Peier et al., 2002; McKemy, 2005). These menthol sensitive neurons are also activitated by capsaicin (McKemy et al., 2002; Viana et al., 2002) and can therefore be categorized as cold and heat responsive neurons. The observed selective effects of menthol in cold pain processing, reinforce previous findings that TRPM8 may be involved in the cold-sensitizing effects of menthol in vivo and is expressed on cold-sensitive nociceptors (Wasner et al., 2004), although it is difficult to extrapolate the molecular findings obtained in animals to human subjects.

We found that menthol had no effect on responses to heat stimuli, consistent with previous findings (Green, 1992; Wasner et al., 2004; Namer et al., 2005). However, recent psychophysical studies have reported significant mechanical pinprick hyperalgesia with menthol (Wasner et al. 2004; Namer et 
al., 2005), whereas this was not observed in our sample. One possible reason for these differences is the higher concentrations of menthol used in these studies (40 \%) than in ours. Wasner et al. (2004) also reported spontaneous burning pain and reddening of the skin after menthol application, which were not observed with the $30 \%$ menthol applications in our study. Such effects, which were also noted in our preliminary experiments using $40 \%$ menthol in a small group of subjects, are probably dose-related. Skin reddening has been attributed to neurogenic vasodilatation (Wasner et al., 2004), but may also result from skin irritation and local skin reaction (Eccles, 1994). Thus, low concentrations of menthol (5 to $10 \%$ ) induce a cooling sensation and have only weak effects on pain perception (Green 1992; Yosipovitch et al., 1996), while high concentrations of menthol probably have stronger but less selective hyperalgesic effects and appear to be irritant for human skin. Skin reddening unmasks blinding in placebo-controlled studies. The absence of spontaneous burning pain or signs of skin irritation after the application of $30 \%$ menthol in our study suggests that the use of this concentration of menthol presents significant clinical advantages in that it may be suitable for use in patients with cold hyperalgesia in future studies.

As in previous psychophysical studies (Green, 1992; Yosipovitch et al., 1996; Wasner et al. 2004; Namer et al., 2005), we used ethanol as a solvent for menthol, because it is difficult to find alternative lipophilic solvents. However, ethanol has been reported to have irritant effects (Wahlberg, 1984; Ophaswongse and Maibach, 1994; Namer et al., 2005). We observed a moderate but significant increase in cold detection thresholds after ethanol but not menthol application. Interestingly, ethanol has been shown to inhibit the 
TRPM8 receptor in a concentration-dependent fashion in vitro (Weil et al., 2005). This inhibition is complete at an ethanol concentration of $3 \%$. Our findings are consistent with these molecular data. As menthol activates the TRPM8 receptor, it would be expected to enhance the detection of cold in humans, but we found no effect of menthol on cold detection thresholds in our study. It may therefore be speculated that the inhibitory effects of ethanol on the perception of non noxious cold may have masked the effects of menthol, thus accounting for the lack of effect of menthol in ethanol on cold detection thresholds, also reported in previous studies (Green, 1992; Wasner et al., 2004; Namer et al., 2005). Thus, the use of ethanol as a solvent for menthol (but also for other compounds such as capsaicin) may not be optimal and may complicate the interpretation of results from experiments carried out with these ligands. An alternative lipophilic solvent for menthol should probably be sought for future studies.

This study also highlights individual variability in psychophysical responses to noxious cold and to menthol, at least under our experimental conditions. A subgroup of our subjects $(20 \%)$ had no pain at baseline in response to the most severe noxious cold stimulus used $\left(5^{\circ} \mathrm{C}\right)$ and, in one third of our sample, menthol elicited no cold allodynia or hyperalgesia. However, we found no correlation between susceptibility to cold pain and menthol-mediated hyperalgesia to cold, suggesting that these psychophysical attributes involved different mechanisms. In vitro, two populations of coldsensitive neurons have been characterized that may be subdivided into predominantly menthol-sensitive neurons and menthol-insensitive neurons, with low and high activation thresholds, respectively (Thut et al., 2003; Nealen 
et al., 2003; Babes et al., 2004). However, the mechanisms of normal noxious cold and of hyperalgesia to cold in humans are probably more complex and remain largely unknown (Davis, 1998). Cold pain is mediated by the activation of Adelta fibers and polymodal C fibers (LaMotte and Thalhammer, 1982), although central disinhibition mechanisms may also be involved (Craig and Buschnell, 1994; Craig et al., 2000). It has been suggested that mechanisms of cold hyperalgesia due to nerve lesions involve a decrease in the inhibition exerted centrally by cold-specific afferents on nociceptors (Wahren et al., 1989; Yarnitsky and Ochoa, 1990; Craig and Buschnell, 1994; Craig et al., 1996), central sensitization to non-nociceptive cold-fiber input (Woolf and Mannion, 1999) or peripheral sensitization of cold-sensitive C nociceptors (Wasner et al., 2004).

Menthol has recently been found to activate both cold specific Adelta fibers and nociceptors in humans (Wasner et al., 2004), which interact negatively centrally (see above). Although a direct effect of menthol on nociceptors may account for its hyperalgesic effects, it is also conceivable that its induced activation of cold specific fibers results in an enhanced inhibition of nociceptive systems. In this perspective, the net hyperalgesic effects of menthol may not only result from nociceptor sensitization, but also depend on a balance between the activation of cold fibers and nociceptors. Interestingly this could account for the individual variability in the response to menthol. It may be proposed, that a poor response to menthol in our experimental conditions relates either to an underexpression of menthol-sensitive receptors on nociceptive fibers or to an overexpression of its receptors on cold fibers. The normal responses of these subjects to noxious cold may result in part 
from the involvement of cold-sensitive but predominantly menthol-insensitive neurons. From a clinical standpoint, it would be interesting to determine whether these "non-responders" to menthol are also less likely to develop cold allodynia or hyperalgesia after a nerve lesion.

Experimental models of hyperalgesia in humans have been developed in recent years as tools for investigating the mechanisms of clinical hyperalgesia and for screening analgesics (Klein et al., 2005). The most widely used model is that induced by intradermal capsaicin administration (Sang et al., 1996; Serra et al., 1998; Hughes et al., 2002) or cutaneous capsaicin application combined with heat (the heat/capsaicin sensitization model) (Petersen and Rowbotham, 1999; Dirks et al., 2002, 2003). In vitro, capsaicin acts on a vanilloid receptor type 1 (TRPV1) from the same family of receptors as those targeted by menthol (Caterina et al., 1997). In humans, capsaicin elicits burning pain, brush-induced allodynia, primary and secondary pinprick hyperalgesia, heat hyperalgesia and neurogenic inflammation but has no effect on cold pain (Petersen and Rowbotham, 1999; Hughes et al., 2002). The secondary mechanical hyperalgesia induced by capsaicin has been widely used as a marker of central sensitization. However, the capsaicin test has a number of limitations, concerning between-subject variability in particular (Liu et al., 1998). In addition, strong burning pain and neurogenic inflammation have precluded its utilization in patients.

Topical menthol application appears to be particularly suitable for the study of cold hyperalgesia in humans. However, although a high concentration of menthol (40\%) elicited dramatic hyperalgesic effects in various situations (Wasner et al., 2004), this concentration is probably too irritant for use in 
patients. The concentration of menthol used in our study (30\%) induced selective effects on cold pain and may be more suitable for use in patients, but was associated with some between-subject variability. In any case, other factors, such as the thickness and condition of the epidermis, the duration of occlusion and the size of the area treated may also influence the perceptual effects of menthol on human skin. Additional studies are required to confirm the validity of the menthol test for studying cold hyperalgesia in healthy volunteers and in patients. These studies should probably attempt to minimize variability by making use of a pre-trial screen, as has been proposed for the capsaicin test (Hughes et al., 2002; Dirks et al., 2003), and should also assess within- and between-day reproducibility in the response to menthol. 


\begin{tabular}{|c|c|c|}
\hline Detection thresholds & Menthol & Vehicle \\
& $(\mathrm{n}=39)$ & $(\mathrm{n}=39)$ \\
\hline Warm detection threshold $\left({ }^{\circ} \mathrm{C}\right)$ & $33,4 \pm 0,7$ & $33,6 \pm 0,8$ \\
Cold detection threshold $\left({ }^{\circ} \mathrm{C}\right)$ & $30,5 \pm 0,9$ & $29,6 \pm 1,7$ ** \\
Mechanical detection threshold $(\log (\mathrm{mg}))$ & $1,8 \pm 0,1$ & $1,8 \pm 0,1$ \\
Vibratory detection threshold $(\mathrm{mA})$ & $3,9 \pm 3,1$ & $3,4 \pm 2,6$ \\
\hline
\end{tabular}

Table 1: Thermal and mechanical detection thresholds after topical application of menthol and vehicle. Vehicle (ethanol) but not menthol induced a significant increase in the cold detection thresholds (ie, reduction of absolute values) ( $F$ $=7.45 ; p<0.001)$ 


\section{Figures Legend}

Figure 1: Effects of menthol and vehicle on cold pain thresholds $(A)$, heat pain thresholds (B) and mechanical pain thresholds (C). There was a significant decrease in cold pain thresholds after menthol, but not vehicle application ( $F=$ $11.6 ; p<0.001)$.

Figure 2: Comparison of the effects of menthol and vehicle on the responses induced by suprathreshold cold (A), heat (B) and mechanical pinprick stimulation (C). Menthol induced a significant increase in the stimulusresponse curve obtained for noxious cold stimulation in comparison with the vehicle $(F=13.5 ; p<0.001)$ without affecting responses to other stimuli. 


\section{References}

Babes A, Zorzon D, Ried G. Two populations of cold-sensitive neurons in rat dorsal root ganglia and their modulation by nerve growth factor. Eur $\mathrm{J}$ Neurosci 2004;20:2276-82.

Bouhassira D, Attal N, Willer JC, Brasseur L. Painful and painless peripheral sensory neuropathies due to HIV infection: a comparison using quantitative sensory evaluation. Pain 1999; 1-2: 265-72.

Caterina MJ, Schumacher MA, Tominaga M, Rosen TA, Levine JD, Julius D. The capsaicin receptor: a heat-activated ion channel in the pain pathway. Nature 1997; 389: 783-4.

Cliff MA, Green BG. Sensory irritation and coolness produced by menthol: evidence for selective desensitization of irritation. Physiol Behav 1994; 56: 1021-9.

Cliff MA, Green BG. Sensitization and desensitization to capsaicin and menthol in the oral cavity: interactions and individual differences. Physiol Behav 1996; 59 :487-94.

Craig AD, Bushnell MC. The thermal grill illusion: unmasking the burn of cold pain. Science 1994; $265: 252-5$.

Craig AD, Chen K, Bandy D, Reiman EM. Thermosensory activation of insular cortex. Nat Neurosci 2000; 3: 184-90

Craig AD, Reiman EM, Evans A, Bushnell MC. Functional imaging of an illusion of pain. Nature 1996; 384: 258-60.

Davis KD. Cold-induced pain and prickle in the glabrous and hairy skin. Pain 1998;75: 47-57. 
Dirks J, Petersen KL, Dahl JB. The heat/capsaicin sensitization model: a methodologic study. J Pain 2003; 4: 122-8.

Eccles R. Menthol and related cooling compounds. J Pharm Pharmacol 1994; 46: 618-30.

Frushstorfer $\mathrm{H}$, Lindblom $\mathrm{U}$, Schmidt WG. Method for quantitative estimation of thermal thresholds in patients. J Neurol Neurosurg Psychiatry 1976; 39: 1071-5.

Green BG. The sensory effects of I-menthol on human skin. Somatosens Mot Res 1992; 9: 235-44.

Green BG. Menthol inhibits the perception of warmth. Physiol Behav 1986; 38: 833-8.

Green BG, Mc Auliffe BL. Menthol desensitization of capsaicin irritation. Evidence of a short-term anti-nociceptive effect. Physiol Behav 2000; 68: 6319.

Hansson P and Lindblom U. Hyperalgesia assessed with quantitative sensory testing in patients with neurogenic pain. In: WD Willis (Ed), Hyperalgesia and Allodynia, Raven Press, New York, 1992, 335-43.

Hughes A, Macleod A, Growcott J, Thomas I. Assessment of the reproducibility of intradermal administration of capsaicin as a model of inducing human pain. Pain 2002;99:323-31.

Jensen TS, Gottrup H, Sindrup SH, Bach FW. The clinical picture of neuropathic pain. Eur J Pharmacol 2001 ;429:1-11.

Klein T, Magerl W, Rolke R, Treede RD Human surrogate models of neuropathic pain. Pain 2005 ; 115-227-233. 
Lamotte $\mathrm{RH}$, Thalhammer JG. Response properties of high-threshold cutaneous cold receptors in the primate. Brain Res 1982;244 :279-87.

Lindblom $U$, Tegner R. Are the endorphins active in clinical pain states? Narcotic antagonism in chronic pain patients. Pain 1979;7:65-8.

Liu M, Max MB, Robinovitz E, Gracely RH, Bennett GJ. The human capsaicin model of allodynia and hyperalgesia: sources of variability and methods for reduction. J Pain Symptom Manage 1998;16 :10-20.

Mc Kemy D. How cold is it? TRPM8 and TRPA1in the molecular logic of cold sensation. Molec Pain 2005;1 :16.

McKemy DD, Neuhausser WM, Julius D. Identification of a cold receptor reveals a general role for TRP channels in thermosensation. Nature 2002; 416: $52-8$.

Namer B, Seifert F, Handwerker HO, Maihofner C. TRPA1 and TRPM8 activation in humans: effects of cinnamaldehyde and menthol. Neuroreport $2005 ; 16: 955-9$.

Nealen ML, Gold MS, Thut PD, Caterina MJ. TRPM8 mRNA is expressed in a subset of cold-responsive trigeminal neurons from rat. J Neurophysiol 2003;90:515-20.

Ophaswongse S, Maibach HI. Alcohol dermatitis: allergic contact dermatitis and contact urticaria syndrome. Contact dermatitis 1994;30:1-6.

Peier AM, Moqrich A, Hergarden AC, Reeve AJ, Andersson DA, Story GM et al. A TRP channel that senses cold stimuli and menthol. Cell;108:705-15.

Petersen KL, Rowbotham MC. A new human experimental pain model: the heat/capsaicin sensitization model. Neuroreport 1999;10 :1511-6. 
Petersen KL, Rowbotham MC. Will ion-channel blockers be useful for management of nonneuropathic pain? J Pain 2000;1: 26-34.

Sang CN, Gracely RH, Max MB, Bennett GJ. Capsaicin-evoked mechanical allodynia and hyperalgesia cross nerve territories. Evidence for a central mechanism. Anesthesiology 1996;85:491-6.

Serra J, Campero M, Ochoa J. Flare and hyperalgesia after intraderml capsaicin injection in human skin. J Neurophysiol 1998;80 :2801-10.

Thut PD, Wrigley D, Gold MS. Cold transduction in rat trigeminal ganglia neurons in vitro. Neuroscience 2003;119:1071-83.

Verdugo RJ, Ochoa JL. "Sympathetically maintained pain". Phentolamine block questions the concept. Neurology 1994;44:1003-10.

Viana F, de la Pena E, Belmonte C. Specificity of cold thermotransduction is determined by differential ionic channel expression.Nat Neurosci. $2002 ; 5$ :254-60.

Wahren LK, Torebjork E, Jorum E. Central suppression of cold-induced C fibre pain by myelinated fibre input. Pain 1989;38:313-9.

Wahlberg JE. Edema-inducing effects of solvents following topical administration. Derm Beruf Unwelt 1984;32:91-4.

Wasner G, Schattschneider J, Binder A, Baron R. Topical menthol - a human model for cold pain by activation and sensitization of $C$ nociceptors. Brain $2004 ; 127: 1159-71$.

Weil A, Moore SE, Waite NJ, Randall A, Gunthorpe MJ. Conservation of functional and pharmacological properties in the distantly related temperature sensors TRPV1 and TRPM8. Mol Pharmacol 2005: in press. 
Woolf CJ, Mannion RJ. Neuropathic pain: aetiology, symptoms, mechanisms, and management. Lancet 1999;353:1959-64.

Yarnitsky D, Ochoa JL. Release of cold-induced burning pain by block of coldspecific afferent input. Brain 1990;113 :893-902.

Yosipovitch G, Szolar C, Hui XY, Maibach H. Effect of topically applied menthol on thermal, pain and itch sensations and biophysical properties of the skin. Arch Dermatol Res 1996;228 :245-8. 
A Cold pain thresholds

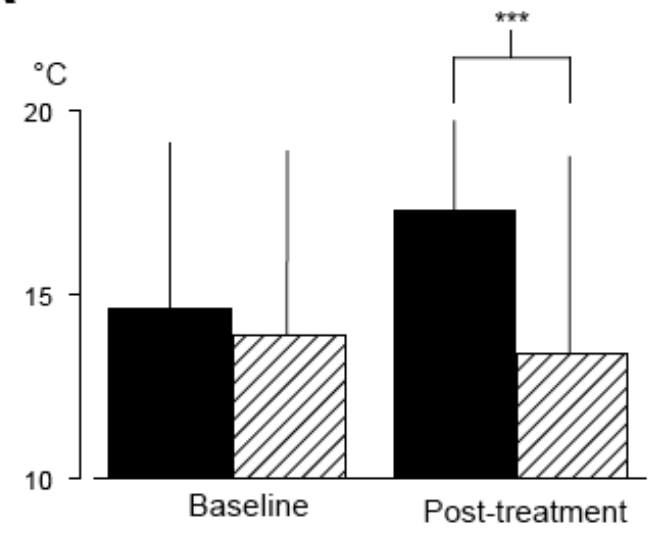

B Heat pain thresholds

${ }^{\circ} \mathrm{C}$

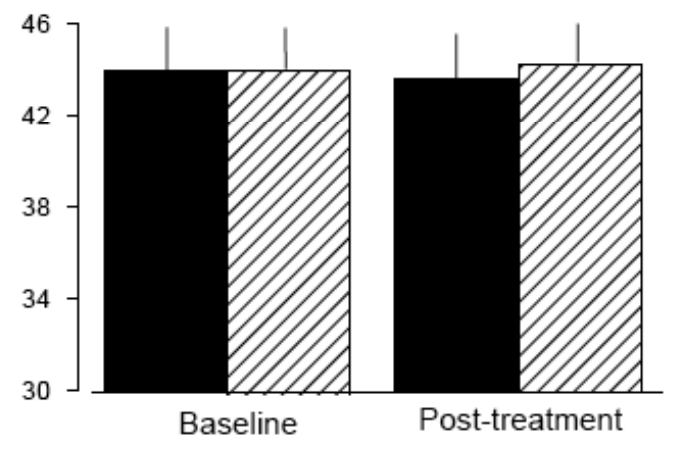

menthol

$\nabla$ placebo

C Mechanical pain thresholds

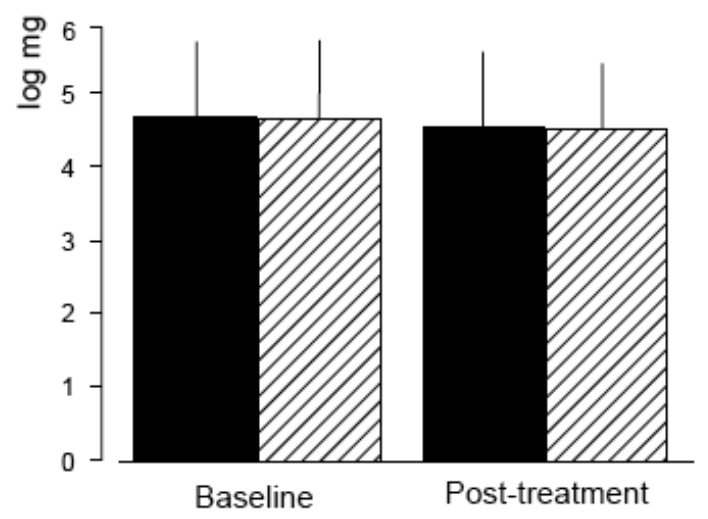

ig. 1 

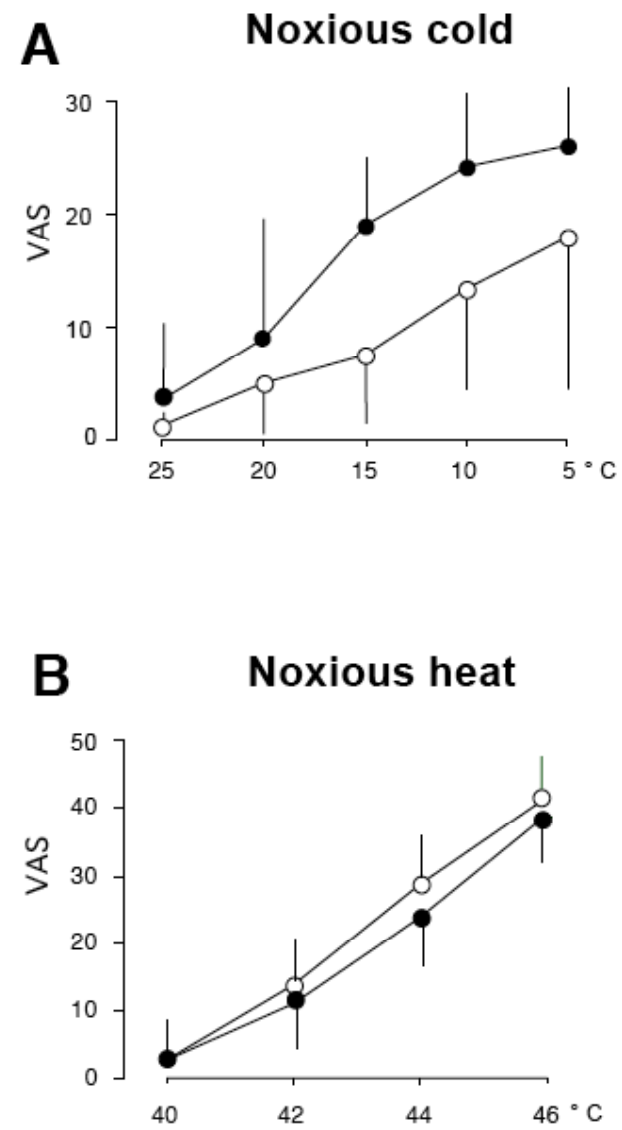

-O- placebo

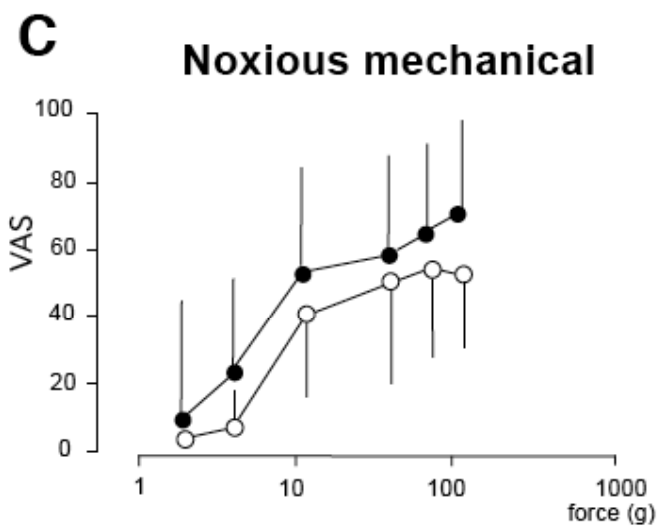

Fig. 2 